\title{
Simultaneous separation of nine metal ions and ammonium with nonaqueous capillary electrophoresis
}

\author{
Feng $\mathrm{Qu}^{\mathrm{a}}$, Jin-Ming Lin ${ }^{\mathrm{a}, *}$, Zuliang Chen ${ }^{\mathrm{b}}$ \\ ${ }^{a}$ Research Center for Eco-Environmental Sciences, Chinese Academy of Sciences, P.O. Box 2871, Beijing 100085, China \\ ${ }^{\mathrm{b}}$ Center for Environmental Risk Assessment and Remediation, University of South Australia, Mawson Lakes, SA 5095, Australia
}

Received 10 June 2003; received in revised form 10 September 2003; accepted 19 September 2003

\begin{abstract}
A simple and fast method for simultaneous separation of nine metal cations $\mathrm{Ni}^{2+}, \mathrm{Cu}^{2+}, \mathrm{Co}^{2+}, \mathrm{Zn}^{2+} \mathrm{Cd}^{2+}, \mathrm{K}^{+}, \mathrm{Na}^{+}, \mathrm{Mg}^{2+}$ and $\mathrm{Ca}^{2+}$, and $\mathrm{NH}_{4}{ }^{+}$in methanol is reported. The optimization for separation these 10 cations was achieved by using $0.5 \%$ acetic acid and $10 \mathrm{mM}$ imidazole as electrolyte. The effects of water and ionic strength in the sample are discussed. The sensitive detection of transition metal ions was accomplished at $191 \mathrm{~nm}$. The optimized method demonstrated high efficiency and good reproducibility, and was applied successfully to the qualitative and quantitative determination of transition metal ions in water samples, chemical reagents, oral zinc gluconate solution and human plasma.
\end{abstract}

(c) 2003 Elsevier B.V. All rights reserved.

Keywords: Nonaqueous capillary electrophoresis; Metal cations; Ammonium

\section{Introduction}

Determination of inorganic cations such as alkali, alkaline earth, $\mathrm{NH}_{4}{ }^{+}$and transition metal ions is of great importance for environmental, medical and pharmaceutical analysis. A simple, rapid and reliable method that can determine these cations in real samples is needed. Ion chromatography (IC) is a popular analytical technique for metal ions analysis in the last two decades. However, IC requires different separation and detection systems for routine cations and transition metal ions, such as different stationary, mobile phases, post-column suppressors and post-column chelating reagent mixing systems [1].

Capillary electrophoresis (CE) is an analytical technique which has developed rapidly during the last ten years. Because of its speed, resolving power, minimal sample and reagent requirements, greater simplicity in operation compared to IC and adaptability to a variety of applications using different separation conditions, it has been applied extensively to many analytes in a variety of areas. Many papers were published on the analysis of alkali, alkaline earth

\footnotetext{
* Corresponding author. Tel.: +86-10-62841953; fax: +86-10-62841952.

E-mail address: jmlin@mail.rcees.ac.cn (J.-M. Lin).
}

and $\mathrm{NH}_{4}{ }^{+}$[2-5] in the early 1990s. Crown ethers have been applied to $\mathrm{CE}$ to improve the separation of $\mathrm{K}^{+}$and $\mathrm{NH}_{4}{ }^{+}[3,5]$. Since then, the separation of many transition metals by CE [6-9] or micellar electrokinetic chromatography (MEKC) $[10,11]$ have been reported. This process is mainly carried out by using complexing agents, which are either added to the electrolyte or to the sample before introduction to the capillary. Janos et al. has reviewed this application in detail [12-14]. The most frequently used complexing agents for most di- and trivalent metal ions are hydroxycarboxylic acids [15], such as $\alpha$-hydroxyisobutyric acid (HIBA), and other complexing agents pyridylazoresorcin (PAR), hydroxyquinoline sulfonic acid (HQS), EDTA, nitrilotriacetic acid (NTA) and crown ethers.

In addition, organic solvents have also been added into electrolyte to improve the selectivity of metal ion separations $[5,13]$. The use of pure nonaqueous systems offers potential for adjustment of relative migration rates via change in solvation-ion interaction. Evidence for such analyte-electrolyte interaction was reported for the separation of inorganic anions [16]. A limited number of studies reported the separation of cations [6] and transition metal ions in pure nonaqueous systems [7].

In this paper, a rapid and reliable method for the separation of ten cations is introduced. Methanol and a weak 
complexing agent, acetic acid, were used for optimizing proper selectivity. The electrolyte produced lower current, thereby allowing the use of a wider internal diameter capillary (100-150 $\mu \mathrm{m}$ i.d.). The sensitive detection of these transition metal ions was obtained at $191 \mathrm{~nm}$. Moreover, the electrolyte was stable and very easy to prepare, avoiding problems associated with adjusting $\mathrm{pH}$ and $\mathrm{pH}$ error between experiments. The method discussed here is very simple and is less time-consuming and labour intensive than many separation methods. It has been applied successfully to the determination of transition metal ions in water samples, chemical reagents, oral zinc gluconate solution and human plasma.

\section{Experimental}

\subsection{Instrumentation}

Experiments were performed with a Beckman P/ACE MDQ system (USA), which comprises a CE unit with diode array detector and workstation. Separations were carried out on fused-silica capillaries of $57 \mathrm{~cm}$ (50 cm effective length) $\times 100$ and $150 \mu \mathrm{m}$ i.d. (Yongnian Optical Fibre Factory, Heibei, China).

\subsection{Chemicals}

All reagents were of analytical grade. Metal salts and glacial acetic acid were purchased from Beijing Chemical Company (Beijing, China). Imidazole was produced by Kanto Chemicals (Tokyo, Japan). Methanol was of chromatographic grade, purchased from Siyou Biology Medical Company (Tianjin China). Metal ion standard stock solutions were prepared by dissolving metal salts in methanol of a concentration of $500 \mu \mathrm{g} / \mathrm{ml}$.

\subsection{Electrophoretic procedures}

The new capillary was rinsed with methanol, water, $1 \mathrm{M}$ $\mathrm{HCl}$ and water for $5 \mathrm{~min}$, and then activated with $1 \mathrm{M} \mathrm{NaOH}$ and water for $30 \mathrm{~min}$, respectively. Between injections the capillary was rinsed with carrier electrolyte for $3 \mathrm{~min}$. The separation was run at a constant temperature of $25^{\circ} \mathrm{C}$ and the voltage applied was $20 \mathrm{kV}$. The detection wavelength utilized was $191 \mathrm{~nm}$. Pressure injection was performed using 0.5 p.s.i. for $5 \mathrm{~s}(1$ p.s.i. $=6894.76 \mathrm{~Pa})$. Electrokinetic injection was performed using $10 \mathrm{kV}$ for $30 \mathrm{~s}$.

\subsection{Sample preparation}

\subsubsection{Water samples}

Two deionized water samples from different laboratories and a deep-ground well water sample were collected freshly, and then injected by electrokinetic injection.

\subsubsection{Chemical reagents}

Organic solvents ethanol, methanol (Fluka), $\mathrm{N}, \mathrm{N}$-dimethylformamide methanol (Fluka) and concentrated hydrochloride acid diluted 1:1,000,000 (v/v) were injected by electrokinetic injection.

\subsubsection{Zinc gluconate solution}

Oral zinc gluconate solution was purchased on market, whose ingredients contain sugar, essence and zinc gluconate compound. The labelled concentration of zinc is $3.53 \mathrm{mg} / 10 \mathrm{ml}$ unit. The solution was diluted 100 times before pressure injection.

\subsubsection{Plasma}

One hundred microliter human plasma was treated by adding $400 \mu \mathrm{l}$ trichloride acetic acid $(50 \mathrm{mg} / \mathrm{ml})$ to remove protein. The mixture was thoroughly mixed and then centrifuged at $4000 \mathrm{rpm}$ for $10 \mathrm{~min}$. The supernatant was diluted by 10 times with methanol before pressure injection.

\section{Results and discussion}

\subsection{Effect on cations mobilities}

In aqueous solution, $\mathrm{K}^{+}$and $\mathrm{NH}_{4}^{+}$could not be separated without adding crown ether to the electrolyte. $\mathrm{Ni}^{2+}$, $\mathrm{Cu}^{2+}, \mathrm{Co}^{2+}, \mathrm{Zn}^{2+}, \mathrm{Cd}^{2+}, \mathrm{Mg}^{2+}$ and $\mathrm{Ca}^{2+}$ are divalent ions with similar mobilities. Weak complexing agents, such as HIBA, are commonly used $[5-7,12]$ to improve their separation. However, organic solvents offer the potential for adjusting relative migration rates. In pure methanol, $\mathrm{NH}_{4}{ }^{+}, \mathrm{K}^{+}$, $\mathrm{Na}^{+}, \mathrm{Mg}^{2+}, \mathrm{Ca}^{2+}, \mathrm{Ni}^{2+}, \mathrm{Cu}^{2+}, \mathrm{Co}^{2+}, \mathrm{Zn}^{2+}, \mathrm{Cd}^{2+}$ can be separated simultaneously using an even weaker complexing agent, acetic acid.

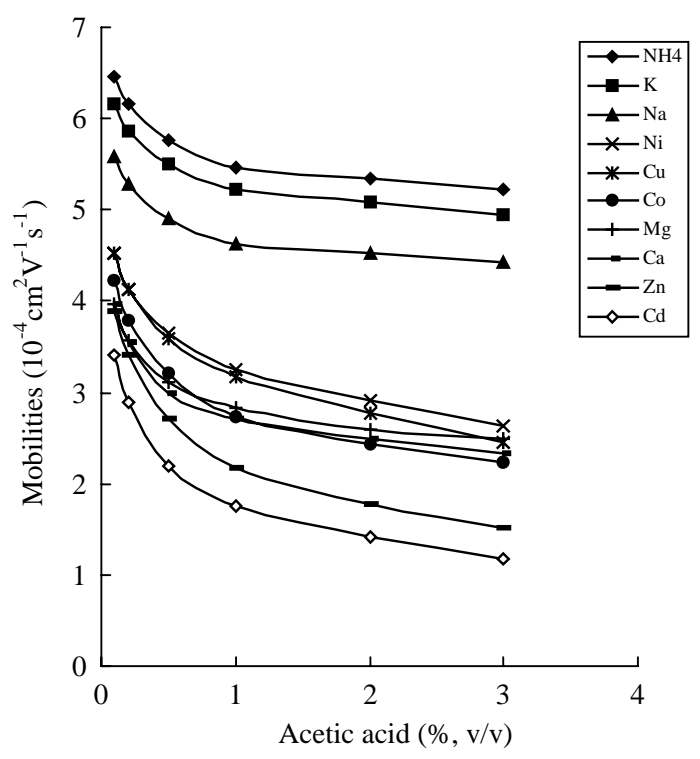

Fig. 1. Dependence of cation mobilities on acetic acid concentration. 
As the acetic acid concentration increased, the mobilities of the cations decreased obviously (Fig. 1). The resolution and migration order of $\mathrm{Ni}^{2+}, \mathrm{Cu}^{2+}, \mathrm{Co}^{2+}, \mathrm{Mg}^{2+}$ and $\mathrm{Ca}^{2+}$ were changed. When using $0.5 \%$ acetic acid, all 10 cations were separated completely. With $1 \%$ acetic acid, the separation efficiency and sensitivity for $\mathrm{Ni}^{2+}, \mathrm{Cu}^{2+}, \mathrm{Zn}^{2+}$ and $\mathrm{Cd}^{2+}$ reached the highest level, but $\mathrm{Co}^{2+}$ overlapped with $\mathrm{Mg}^{2+}$ and $\mathrm{Ca}^{2+}$.

Fig. 2 shows the change in cation mobilities with increasing imidazole concentration. When the imidazole concentration was lower than $5 \mathrm{mM}, \mathrm{Co}^{2+}$ could no longer be detected. When the imidazole concentration became higher than $10 \mathrm{mM}$, the peaks for $\mathrm{Ni}^{2+}$ and $\mathrm{Cu}^{2+}$ partially overlapped. In addition, as the imidazole concentration increases, the mobilities of $\mathrm{Mg}^{2+}$ and $\mathrm{Ca}^{2+}$ decreased faster than the other di-valent ions. The migration order of $\mathrm{Co}^{2+}, \mathrm{Mg}^{2+}$, $\mathrm{Ca}^{2+}$ and $\mathrm{Zn}^{2+}$ was different in the $10-20 \mathrm{mM}$ imidazole concentration range. An amount of $10 \mathrm{mM}$ imidazole was chosen as the optimal concentration for this experiment.

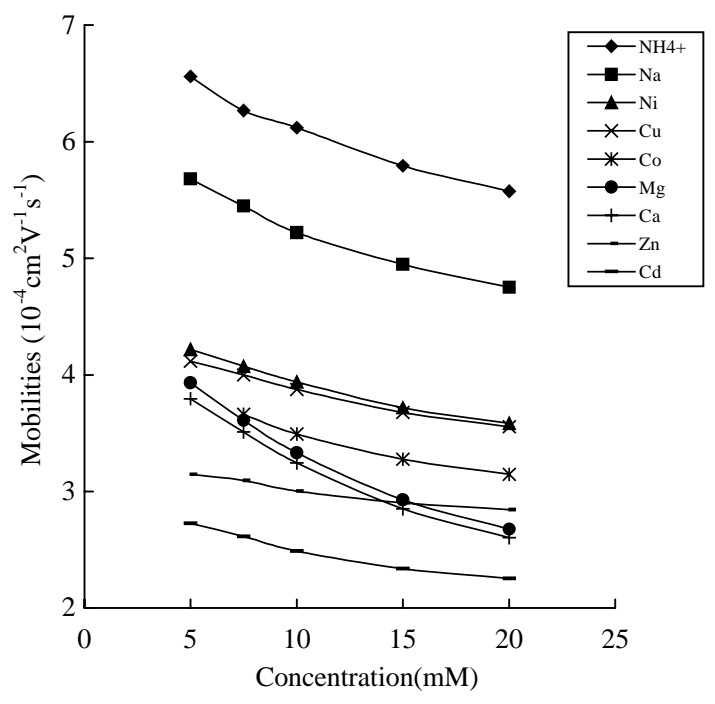

Fig. 2. Dependence of cation mobilities on imidazole concentration.

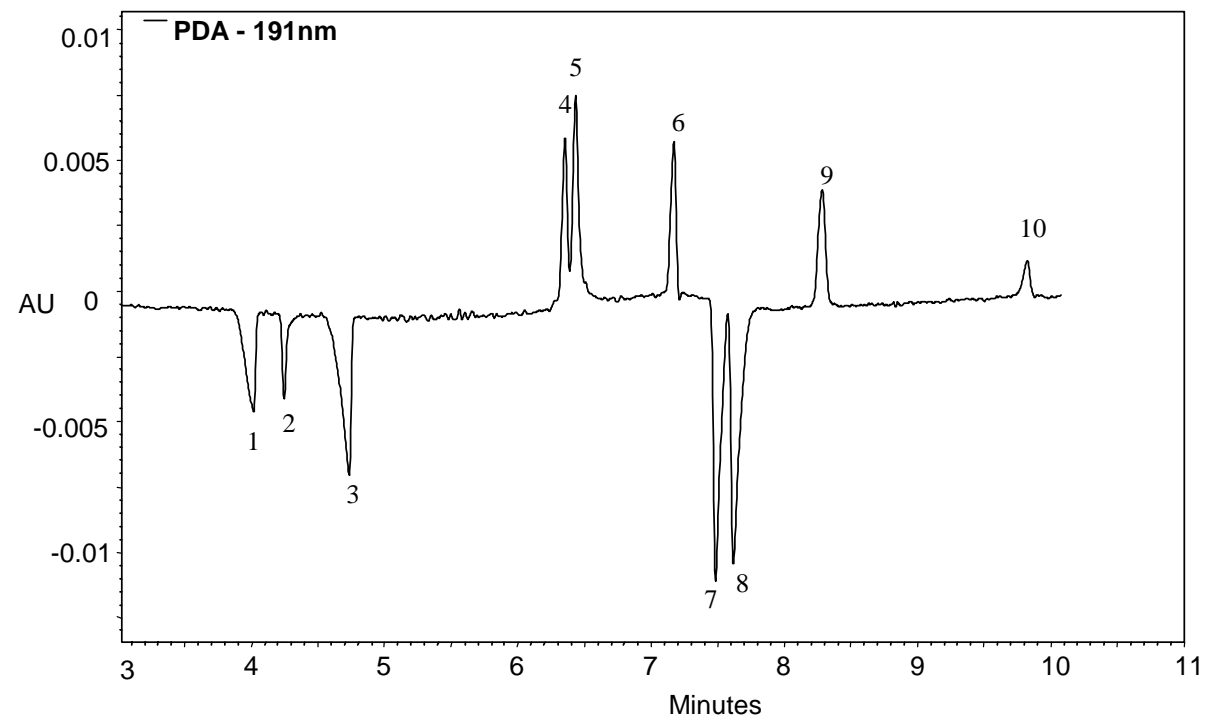

Fig. 3. Electropherogram of $5 \mu \mathrm{g} / \mathrm{ml}$ cations. Electrolyte: $0.5 \%$ acetic acid and $10 \mathrm{mM}$ imidazole in methanol; $20 \mathrm{kV}$; $191 \mathrm{~nm}$; pressure injection, $0.5 \mathrm{p} . \mathrm{s} . \mathrm{i}$.; 5 s. Peak (1) $\mathrm{NH}_{4}^{+}$; (2) $\mathrm{K}^{+}$; (3) $\mathrm{Na}^{+}$; (4) $\mathrm{Ni}^{2+}$; (5) $\mathrm{Cu}^{2+}$; (6) $\mathrm{Co}^{2+}$; (7) $\mathrm{Mg}^{2+}$; (8) $\mathrm{Ca}^{2+}$; (9) $\mathrm{Zn}^{2+}$; (10) $\mathrm{Cd}^{2+}$. PDA: photodiode array detection.

Table 1

Efficiency, linear range, detection limit and relative standard deviation

\begin{tabular}{|c|c|c|c|c|c|c|c|c|}
\hline \multirow[t]{2}{*}{ Cations } & \multicolumn{2}{|c|}{ Theoretical plates number $(N)$} & \multicolumn{2}{|c|}{ Linear range $\left(r^{2}\right)(\mu \mathrm{g} / \mathrm{ml})$} & \multicolumn{2}{|c|}{ Detection limit $(\mu \mathrm{g} / \mathrm{ml})$} & \multicolumn{2}{|l|}{ R.S.D. $(\%)^{\mathrm{a}}$} \\
\hline & $100 \mu \mathrm{m}$ i.d. & $150 \mu \mathrm{m}$ i.d. & $100 \mu \mathrm{m}$ i.d. & $150 \mu \mathrm{m}$ i.d. & $100 \mu \mathrm{m}$ i.d. & $150 \mu \mathrm{m}$ i.d. & Migration time & Peak area \\
\hline $\mathrm{Ni}^{2+}$ & 95377 & 26800 & $1-80(0.9975)$ & $0.2-40(0.9988)$ & 0.25 & 0.1 & 0.93 & 9.79 \\
\hline $\mathrm{Cu}^{2+}$ & 102800 & 37800 & $1-80(0.9990)$ & $0.1-40(0.9991)$ & 0.25 & 0.05 & 1.09 & 3.10 \\
\hline $\mathrm{Co}^{2+}$ & 99800 & 34400 & $1-20(0.9978)$ & $1-20(0.9975)$ & 0.25 & 0.1 & 1.12 & 7.19 \\
\hline $\mathrm{Zn}^{2+}$ & 94200 & 38000 & $1-80(0.9998)$ & $0.1-40(0.9998)$ & 0.15 & 0.05 & 1.41 & 10.7 \\
\hline $\mathrm{Cd}^{2+}$ & 116300 & 42100 & $5-80(0.9984)$ & $1-20(0.9990)$ & 1 & 0.5 & 1.75 & 16.5 \\
\hline $\mathrm{Mg}^{2+}$ & 39800 & & & & & & 1.11 & 11.4 \\
\hline $\mathrm{Ca}^{2+}$ & 41000 & & & & & & 1.04 & 22.8 \\
\hline $\mathrm{K}^{+}$ & 28800 & & & & & & 0.35 & 18.8 \\
\hline $\mathrm{Na}^{+}$ & 17800 & & & & & & 0.46 & 5.71 \\
\hline $\mathrm{NH}_{4}^{+}$ & 7800 & & & & & & 0.37 & 5.87 \\
\hline
\end{tabular}

Conditions: $0.5 \%$ acetic acid and $10 \mathrm{mM}$ imdazole.

a $5 \mu \mathrm{g} / \mathrm{ml}$ of 10 cations, $n=5$. 

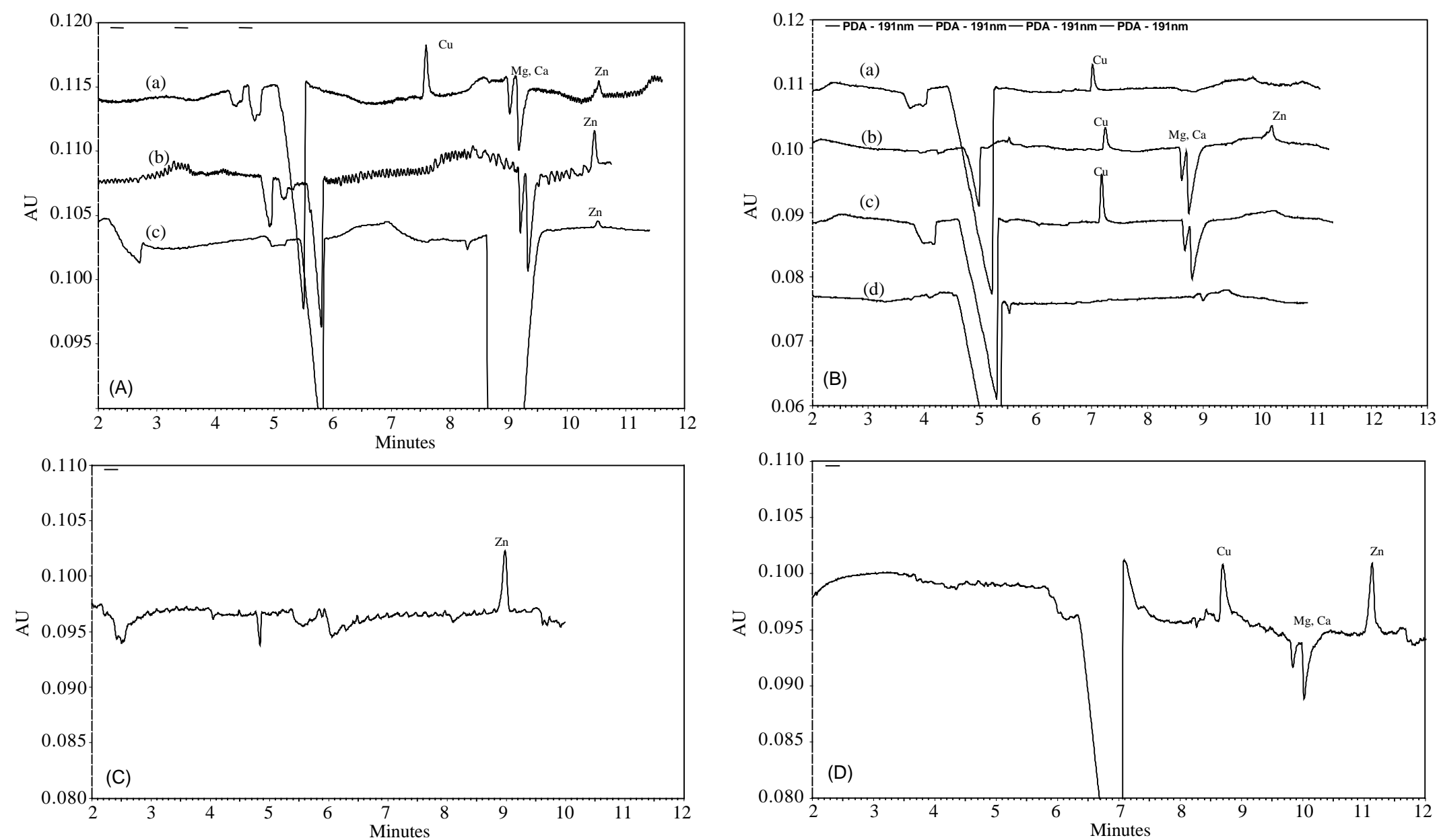

Fig. 4. Samples analysis. (A) Water sample analysis: (a and b) deionized water from different lab; (c) deep-ground well water. (B) Chemical reagent analysis: (a) ethanol; (b) concentrated hydrochloride

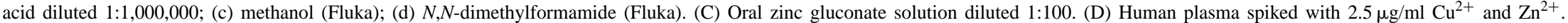


The influence of water content in sample was investigated considering that most samples are in aqueous solution. When samples were dissolved in water, the migration times of the cations were slightly shorter than in pure methanol, and the efficiency did not change. However, the peak area for $\mathrm{Ca}^{2+}$ increased and the resolution between $\mathrm{Ni}^{2+}$ and $\mathrm{Cu}^{2+}$ was improved, both characters has being beneficial to real sample analysis.

The effect of ionic strength on the migration time of these cations was investigated by adding increasing concentration of $\mathrm{KCl}$ to the mixture of nine cations in standard solution. When the $\mathrm{KCl}$ concentration was higher than $0.5 \mathrm{mM}$, the $\mathrm{NH}_{4}{ }^{+}$peak disappeared. There were no obvious effects on migration time and efficiency for the other nine cations as the $\mathrm{KCl}$ concentration was increased from 0.01 to $1 \mathrm{mM}$.

\subsection{Method validation}

With $20 \mathrm{kV}$ applied, the electrolyte gave currents of 9.4 and $15.2 \mu \mathrm{A}$, respectively, with 100 and $150 \mu \mathrm{m}$ i.d. capillary. The detection sensitivity with a $150 \mu \mathrm{m}$ i.d. capillary was 2-5 times higher, but the linear range was shorter and efficiency was 2-3 times lower (Table 1). Therefore, all further experiments were carried out using a $100 \mu \mathrm{m}$ i.d. capillary. Fig. 3 shows the electropherogram for the complete separation of ten cations.

Table 1 details the efficiency, linear range, detection limit and relative standard deviation (\%) for migration time and peak area. The theoretical plates $(N)$ attained for transition metal ions were between 94,200 and 116,300, while other cations were between 7800 and 41,000. The calibration graphs were linear for five transition metal ions using pressure injection mode. The relative standard deviation (R.S.D.) values of five successive injections of a 10 cation mixture were between 0.35 and $1.75 \%$ for migration time and 3.1 and $22.8 \%$ for peak area.

Electrokinetic injection mode could be used to accumulate cations when their concentration was lower than the detection limit. By using electrokinetic injection of $10 \mathrm{kV}$ for $30 \mathrm{~s}$, the detection limits for $\mathrm{Ni}^{2+}$ and $\mathrm{Co}^{2+}$ reached $0.8 \mathrm{ng} / \mathrm{ml}$, $\mathrm{Cu}^{2+}$ and $\mathrm{Zn}^{2+}$ reached 0.2 and $0.5 \mathrm{ng} / \mathrm{ml}$, respectively.

\subsection{Sample analysis}

The method developed here can be applied to real sample analysis. The potential for qualitative and quantitative analysis of cations in various water samples, organic and inorganic chemical reagents, oral zinc gluconate solution and human plasma was investigated (Fig. 4). Fig. 4A shows the analysis of deionized water from different laboratories and a deep-ground well water source. In Fig. 4B, cations in various organic solvents (a, c, d) and mineral acid (b) were detected. Trace levels of $\mathrm{Cu}^{2+}$ and $\mathrm{Zn}^{2+}$ could be detected by enrichment with electrokinetic injection. This method can also be applied to pharmaceutical and plasma analysis. The analysis of zinc in gluconate solution was in good agreement with the labelled amount (Fig. 4C). The recovery of spiked levels of $\mathrm{Zn}^{2+}$ and $\mathrm{Cu}^{2+}$ in human plasma was satisfactory, as well (Fig. 4D).

\section{Acknowledgements}

The authors wish to thank the financial support of the National Science Fund for Distinguished Young Scholars of China (No. 20125514), National Natural Science Foundation of China (Nos. 20275043 and 50273046) and the National High Technology Research and Development Program of China (863 Program) (No. 2001AA630503).

\section{References}

[1] H. Small, Ion Chromatography, Plenum Press, New York, 1989.

[2] A. Weston, P.R. Brown, J. Chromatogr. 608 (1992) 395.

[3] W. Beck, H. Engelhardt, Fresenius J. Anal. Chem. 346 (1993) 618.

[4] Y.H. Lee, T.I. Lin, J. Chromatogr A 675 (1994) 227.

[5] Q. Yang, J. Smeyers-Verbeke, W. Wu, M.S. Khots, D.L. Massart, J. Chromatogr. A 688 (1994) 339.

[6] H. Salimi-Moosavi, R.M. Cassidy, J. Chromatogr. A 749 (1996) 279.

[7] K.D. Altria, M. Wallberg, D. Westerlund, J. Chromatogr. B 714 (1998) 99.

[8] N. Shakulashvili, T. Faller, H. Engelhardt, J. Chromatogr. A 895 (2000) 205.

[9] J. Xu, Z. Chen, J.C. Yu, C. Tang, J. High Resolut. Chromatogr. 23 (2000) 511.

[10] A.R. Timerbaev, O.P. Semenova, P. Jandik, G.K. Bonn, J. Chromatogr. A 671 (1994) 419.

[11] E.F. Hilder, M. Macka, P.R. Haddad, Analyst 123 (1998) 2865.

[12] P. Janos, J. Chromatogr. A 834 (1999) 3.

[13] A.T. Timerbaev, J. Chromatogr. A 792 (1997) 495.

[14] V. Packkova, P. Coufal, K. Stulik, J. Chromatogr. A 834 (1999) 257.

[15] C. Vogt, G.L. Klunder, Fresenius J. Anal. Chem. 370 (2001) 316.

[16] H. Salimi-Moosave, R.M. Cassidy, Anal. Chem. 67 (1995) 1067. 